\title{
ANTIBIOTICOS PROFILATICOS EM NEUROCIRURGIA
}

\author{
REYNALDO A. BRANDT* \\ HALLIN FTERES JUNIOR *
}

O valor da administração de antibióticos profilaticamente no período pósoperatório, em doentes neuro-cirúrgicos, não está ainda bem estabelecido. Apesar da importância dos agentes antimicrobianos no tratamento das infecções, seu valor na prevenção das mesmas não foi demonstrado, exceto em algumas exceções específicas. A administração de antibióticos profiláticos é prática comum na especialidade neurocirúrgica. Com o fim de saber se a mesma é útil na prevenção de infecções pós-operatórias, estudamos o seu índice em um grupo de pacientes que receberam antibióticos no período pós-operatório, comparando-o com outro de pacientes que não os receberam.

\section{MATERIAL E METODO}

Foram estudados 73 pacientes submetidos a cirurgias cranianas a raqueanas. Os pacientes foram operados numa mesma sala cirúrgica, sendo constantes as condições ambientais no período pós-operatório de hospitalização. Dos 73, 32 pacientes eram do sexo masculino e 41 do feminino; a idade variou de 1 a 82 anos, com a média de 44,7 anos, havendo apenas 4 menores de 10 anos; 53 apresentavam afecç̃es intracranianas e 20 afecç̃es intrarraqueanas. Fm nenhum havia infecção de qualquer natureza no periodo pré-operatório imediato. Dos pacientes com afecços intracranianas, $72 \%$ apresentaram quadro de natureza considerada grave, o mesmo ocorrendo em 55\% daqueles com afecç̋es intrarraqueanas. Assim, 67\% do total apresentaram afeç̧̃es neurológicas graves como tumores, hemorragias meníngeas consequentes a aneurismas e angiomas e traumatismos com comprometimento neurológico importante.

Antibióticos de largo expectro foram administrados a 53 pacientes, sendo que 20 outros năo os receberam. No primeiro grupo, a ampicilina foi administrada a $8 \%$ dos casos, na dose de 0,5 a $1 \mathrm{~g}$ a cada 6 horas, sendo que os demais receberam cloranfenicol na dose de $0,5 \mathrm{~g}$ a cada 6 horas. Estes antibioticos foram mantidos por um mínimo de 3 dias e em média 7 dias após a cirurgia. Quando verificada uma infecçáo, sempre que possível foi determinado o agente causal e determinado o antibiótico especifico para o combate ao mesmo. Todos os pacientes com afeccores graves receberam dexametasona na dose de $4 \mathrm{mg}$ a cada 4 a 6 horas. Năo houve diferença quanto à gravidade da afecçăo neurológica nos pacientes que receberam e que nåo receberam antibióticos.

Trabalho realizado no Serviço de Neuro-cirurgia do Hospital do Servidor Público Estadual (Serviço do Dr. Joăo Teixeira Pinto): "Neuro-cirurgiăo; * Residente. 


\section{RESULTADOS}

Do total de pacientes, $19,17 \%$ apresentaram infeç̧̃es no periodo pós-operatório. Estas bcorreram em $20,75 \%$ dos pacientes com afeç̧̃es cranio-encefálicas em em $15 \%$ daqueles com afeç̧̃es intrarraqueanas. Infecçðes ocorreram em $27 \%$ dos pacientes com afeç̧ão neurológica grave e em apenas $4 \%$ daqueles com afecção não-grave.

Indice de infeçסes com e sem uso de antibioticos profildticos - Dos pacientes que receberam antibióticos, 26,4\% apresentaram infeç̋es; dos que não receberam antibióticos, nenhum apresentou infecção no período pós-operatório: a diferença entre estes dois grupos é estatisticamente significante ao nível de $2 \%$. Dos pacientes com afeçð̃es intracranianas e que receberam antibióticos, $27,5 \%$ apresentaram infeç̧̃es, sendo que nenhum caso foi verificado nos que năo receberam antibióticos; a diferença entre estes dois grupos é estatisticamente significante ao nível de 5\%. Dos doentes com afecçбes intrarraqueanas e que receberam antibioticos, 23,07\% apresentaram infecções; dos que não receberam antibióticos, nenhum apresentou infecção pós-operatória; a diferença entre estes dois grupos não chega a ser estatisticamente significante ao nivel de 5\%. Dos 14 pacientes que apresentaram infecç̃es, 11 faleceram; em 9 destes a infecção foi a causa direta do óbito. Em 8 casos ocorreu broncopneumonia, que em um se associou a meningite e em outro a septicemia; outro caso faleceu em consequência de meningite e ventriculite após infecção do retalho cutáneo da craniotomia.

Indice de infecsós segundo a gravidade do quadro neurológico - 67\% do total de pacientes apresentaram afeç̧ão grave do sistema nervoso central. $\mathrm{Em} 27 \%$ destes houve infecção pós-operatória, o que ocorreu em apenas $4 \%$ dos pacientes com afeçz̃es não-graves; a diferença entre estes dois grupos é estatísticamente significante ao nivel de 5\%. Dos pacientes com afeção grave e que receberam antibióticos, 32,5\% apresentaram infeç̧ס̃es; dos que não receberam antibiótioos, nenhum apresentou infecçăo. Dos pacientes com afeç̧óes não-graves, 9\% dos que receberam antibióticos desenvolveram infecçర̃es; nenhum dos que não receberam antibióticos apresentou infecção pós-operatória.

\section{COMENTARIOS}

Nos 73 pacientes em que foi estudada a incidência de infecções pós-operatórias com e sem uso de antibióticos profiláticos, verificamos que estas ocorreram numa proporção significativamente maior naqueles em que foram utilizados antibióticos. A diferença foi significante para o grupo como um todo e particularmente para os pacientes com afecções intracranianas. Infecções ocorreram também numa proporção significantemente maior nos pacientes com afecções graves, sendo incomuns nos pacientes com afecções não graves do sistema nervoso central.

$O$ efeito benéfico dos antibióticos no tratamento das infecções tem sido largamente demonstrado ?. No entanto, o seu uso como agente preventivo de infecções não tem demonstrado os mesmos resultados favoráveis ${ }^{11,15}$, com algumas exceções específicas ${ }^{15}$; é o caso das exposições transitórias ao Streptococcus do grupo A e ao bacilo da tuberculose 14,15, bem como das contaminações 
cirúrgicas, particularmente em pacientes submetidos a cirurgias do trato digestivo ${ }^{2,3,5,6,9,16,20}$ e urinário ${ }^{15}$. Mesmo nestas condições, alguns autores contestam a validade do uso de antibióticos profiláticos ${ }^{1}$. A contaminação nestes casos é quase sempre endógena ${ }^{4}$. $O$ indice de infecções pós-operatórias não se modifica com a redução do número de bactérias do ambiente cirúrgico, obtida com o uso de luz ultra-violeta ${ }^{15}$.

Antibióticos profiláticos em pacientes com distúrbios imunológicos ou sob terapêutica imunossupressora mostram resultados decepcionantes e frequentemente catastróficos; resultam em infceções graves, à semelhança do que ocorre em pacientes em coma e nos queimados. Nestes, a antibioticoterapia não só falha na redução dos índices de letalidade, como favorece o aparecimento de infecções por germes resistentes aos antibióticos usuais 15,14.

Goodpasture e col. ${ }^{8}$ estudaram o efeito de antibióticos administrados a pacientes com traumatismo encefálico e entubação traqueal. Sua administração levou ao aparecimento rápido de germes Gram-negativos e infecções graves devidas aos mesmos. Os pacientes não tratados apresentaram infecções geralmente leves e devidas a germes suscetíveis a drogas altamente eficazes e seguras. Nestes casos, o uso de antibióticos de largo expectro profilaticamente não preveniu o desenvolvimento de infecções e provavelmente levou a um aumento do indice de infecções pulmonares graves.

Laszlo e col.13 notaram que a administração de antibióticos a pacientes bronquiticos que foram submetidos a cirurgias eletivas não foi capaz de impedir o aparecimento de complicações respiratórias infecciosas.

Romig e col.10 estudaram pacientes com traumatismo cranio-encefálico agudo internados em unidade de terapia intensiva. Notaram alterações múltiplas da flora bacteriana, particularmente no trato respiratório, e morbidade significativa decorrente destas alterações. A mortalidade correlacionou-se diretamente com a gravidade da doença e com a proliferação de germes Gram-negativos no trato respiratório.

A prevalência de germes Gram-negativos na flora bacteriana do oro-faringe é baixa nos indivíduos normais, em condições fisiológicas, mesmo quando expostos a ambiente hospitalar. Em doentes com patologias de gravidade variável, esta prevalência aumenta proporcionalmente à gravidade da doença e não se correlaciona com o tempo de permanência no hospital 12. A administração de antibióticos suprime rapidamente os microrganismos inibidores do crescimento de germes patogênicos na faringe, levando a alteração do equilíbrio bacteriano e favorecendo a multiplicação de germes patogênicos ${ }^{18}$.

Price \& Sleigh 17 relatam que uma epidemia de infecções devidas a Klebsiella aerogenes verificada em uma unidade de terapia intensiva neurocirúrgica levou a uma infecção toráxica em cada 4 pacientes e uma infecção urinária em cada 8 pacientes, além da ocorrência de 8 casos de meningite fatal devida a este germe. $O$ isolamente dos casos infectados e seu tratamento com antibiótico específico não foram suficientes para debelar o surto. A suspensão do uso de antibióticos nesta unidade, tanto profilática quanto terapeuticamente, levou a uma queda drástica da incidência de infecções por Klebsiella, bem como por outros microrganismos. 
Numa revisão da literatura referente ao uso profilático de antibióticos e agentes quimioterápicos, Hobbs 10 conclui que há pouco lugar para tal prática de maneira rotineira, exceto em poucas condições. A esterilização da pele é importante na redução do índice de infecções da ferida operatória, mas nenhum composto químico substitui a técnica cirúrgica cuidadosa.

\section{CONCLUSOES}

1 - A administração rotineira de antibióticos de largo expectro no período pós-operatório de pacientes neuro-cirúrgicos, que não apresentavam infecção anteriormente à cirurgia, não foi capaz de evitar o aparecimento de infecções pós-operatórias.

2 - As infecções pós-operatórias de pacientes que receberam antibióticos profiláticos foram graves $\mathrm{e}$ fatais na maioria dos casos; predominaram as infecções broncopulmonares, que se associaram a meningite em um caso e a septicemia em outro. Tal se deve, possivelmente, ao fato de a administração de antibióticos de largo expectro suprimir rapidamente os microrganismos inibidores do crescimento de germes patogênicos, levando a alteração do equilíbrio microbiano no organismo. Nos doentes com patologias graves, a prevalência de germes Gram-negativos na flora bacteriana do orofaringe aumenta proporcionalmente à gravidade da doença. Estes fatores, isolada e associadamente, favorecem o desenvolvimento de infecções graves, frequentemente fatais, predominando as do trato respiratório e que não respondem adequadamente à antibioticoterapia.

3 - Pacientes neuro-cirúrgicos, com afecções não-infeccicsas e que não receberam antibióticos profiláticos no período pós-operatório, apresentaram um indice de infecções significativamente menor neste período. Esta constatação foi particularmente evidente nos pacientes com afecções intracranianas graves.

4 - Não há indicação para o uso de antibióticos profiláticos no período pós-operatório de pacientes com afecções neuro-cirưrgicas não-infecciosas. Não há droga capaz de substituir a boa técnica cirúrgica, aliada aos cuidados de esterilização e desinfecção, na prevenção de infecções pós-operatórias.

RESUMO

$O$ indice de infecções pós-operatórias em pacientes neuro-cirúrgicos que receberam antibióticos profiláticos neste período foi comparado com o de pacientes que não receberam antibióticos. Infecções ocorreram em proporções significativamente maiores nos pacientes que receberam antibióticos, particularmente naqueles com afecções intracranianas graves; estas infecções foram graves e fatais na maioria dos casos. A administração de antibióticos profiláticos nestes pacientes não só foi incapaz de prevenir o aparecimento de infecções pós-operatórias, como aparentemente favoreceu o seu desenvolvimento. Tal se deveu, provavelmente, à destruição do equilíbrio microbiano no organismo, favorecendo o desenvolvimento de germes patogênicos e resistentes aos antibióticos usuais 


\section{SUMMARY}

\section{Prophylactic antibiotics in Neurosurgerv}

The post-operative infection-rate in neurosurgical patients who received prophylactic antibiotics was compared to the infection-rate of patients who received no antibiotics. None of the 73 studied patients had pre-operative infection. Infections occured in $26,4 \%$ of the patients in the first group and in none of the second group $(\mathrm{p}<0,2) ; 27,5 \%$ of the patients with intracranial lesions and $9 \%$ of the patients with spinal lesions in the first group had post-operative infections, and none in the second group $(\mathrm{p}<0,05$ and $0.05<\mathrm{p}<0.1$ ). $67 \%$ of all the patients had severe neurological lesions; $27 \%$ of these had post-operative infections; only $4 \%$ of the patients with mild lesions had infections $(p<0.05)$. Post-operative infections were severe and fatal in most of these cases. Prophylactic broad-spectrum antibiotics were of no value in preventing post-operative infections in these neurosurgical patients and those who received no antibiotics had a significantly lower rate of infections.

\section{REFERENCIAS}

1. ALTEMEIER, W. A.; CULBERTSON, W. R. \& HUMMEL, R. P. - Surgrcal considerations of endogenous infections; sources, types, and methods of control. Surg. Clin. N. Amer. 48:227, 1968.

2. BERNARD, H. R. \& COLE, W. R. - The prophylaxis of surgical infections: the effect of prophylactic antimicrobial drugs on the incidence of infection following potentially contaminated operations. Surgery 56:151, 1964.

3. CAMPBEL, P. C. - Large doses of penicillin in the prevention of surgical wound infection. Lancet II:805, 1965.

4. DAVIDSON, A. I. G., SMITH, G. \& SMYLE, H. G. - A bacteriological study of the immediate environment of surgical wound. Brit. J. Surg. 58:326, 1971.

5. EVANS, C.; POLLOCK, A. V. \& ROSEMBERG, I. L. - The reduction of surgical wound infections by topical cephaloridine: a controlled clinical trial. Brit. J. Surg. 61:133, 1974.

6. FEATHERS, R. S.; SAGOR, G. R.; LEWIS, A. A. M.; AMIRAK, I. D. \& NOONE, P. - Prophylactic system antibiotics in colorectal surgery. Lancet II:4, 1977.

7. FORGAN-SMITH, W. R. - Antibiotics and surgery. British J. Hospital Medicine. (London) 14:529, 1975.

8. GOODPASTURE, H. C.; ROMIC, D. A.; VOTH, D. W.; LIU, C. \& BRACKETT, C. E. - A prospective study of tracheobronchial bacterial flora in acutely braininjured patients with and without antibiotic prophylaxis. J. Neurosurg. 47:228, 1977.

9. GRIFFITHS, D. A.; SIMPSON, R. A.; SHOREY, B. A.; SPELLER, D. C. E. \& WILLIAMS, N. B. - Single-dose peroperative antibiotic prophylaxis in gastointetinal surgery. Lancet II:325, 1976. 
10. HOBBS, K. E. F. - Chemoprophylaxis in surgery. Postgraduate Med. J. (Oxford) 52:567, 1976.

11. HUNT, T. K.; ALEXANDER, J. W.; BURKE, J. F. \& MACLEAN. L. D. Antibiotics in surgery. Arch. Surg. 110:148, 1975.

12. JOHANSON, W. G.; PIERCE, A. K. \& SANFORD, J. P. - Changing pharyngeal bacterial flora of hospitalized patients: emergence of Gram-negative bacilli. $N$. England J. Med. 281:1137, 1969.

13. LASZLO, G.; ARCHER, G. G.; DARRELL, J. H.; DAWSON, J. M. \& FLETCHER, C. M. - The diagnosis and prophylaxis of pulmonary complications of surgical operation. Brit. J. Surg. 60:129, 1973.

14. MORTIMER, E. A. - Rational use of prophylactic antibiotics in children. Pediat. Clin. N. Amer. 15:261, 1968.

15. OSELKA, G. M.; LEVI, G. C.; LOPES, H. V.; MENDONÇA, J. S.; ALY, J.; BALDY, J. L. S.; SANTOS, R. R. \& AMATO NETO, V. - Antibióticos na Prática Médica. Ed. Gremed, São Paulo, 1972.

16. POLK, H. C. \& LOPEZ-MAYOR, J. F. - Postoperative wound infection: a prospective study of determinant factors and prevention. Surgery 66:97, 1969.

17. PRICE, D. J. E. \& SLEIGH, J. D. - Control of infection due to Rlebsiella aerogenes in a neurosurgical unit by withdrawal of all antibiotics. Lancet II:1213, 1970.

18. SPRUNT, K. \& REDMAN, W. - Evidence suggesting importance of role of interbacterial inhibition in maintaining balance of normal flora. Ann. Intern. Med. 68:519, 1968.

19. ROMIG, D. A.; VOTH, D. W.; LIU, C. \& BRACKETT, C. E. - Bacterial flora and infection in patients with brain injury. J. Neurosurg. 38:710, 1973.

20. STOKES, E. J.; WATERWORTH, P. M.; FRANKS, V.; MATSON, B. \& CLARCK, C. G. - Short term routine antiblotic prophylaxis in surgery. Brit. J. Surg. 61: 739, 1974.

Praca Charles Miller 8 - 012s4 Sđo Paulo, SP - Brasil. 